\title{
Physical Activity and Cancer: It is Never Too Late to Get Moving!
}

\author{
Duclos Martine \\ ${ }^{1}$ Department of Sport Medicine and Functional Explorations, University-Hospital (CHU), \\ Hopital G. Montpied, Clermont-Ferrand \\ 2 INRA, UMR 1019, Clermont-Ferrand \\ ${ }^{3}$ University Clermont 1, UFR Médecine, Clermont-Ferrand \\ ${ }^{4} \mathrm{CRNH}$-Auvergne, Clermont-Ferrand
}

France

\section{Introduction}

In terms of prevalence, the most common cancers in men and women worldwide are breast cancer (3.9 million breast cancer cases) and colorectal cancers (2.4 million). Moreover, the worldwide incidence of breast and colorectal cancers is destined to increase substantially in the next few decades. Therefore, the prevention of the occurrence of these various types of cancers represents a real stake in public health for which physical activity could play an important role. Indeed, numerous studies showing an association between prevention of these cancers and physical activity have been published these last years.

The number of survivors after treatment of a cancer ("cancer survivors") is also increasing. Since last years, different studies have rocked the research community involved in cancer survivorship. These studies reported a significant protective association between increased physical activity that occurred after the diagnosis of breast or colon cancer and recurrence, cancer-related mortality, and overall mortality among breast cancer or colon cancer survivors.

This chapter will consider epidemiologic evidence regarding the association between physical activity and breast and colon cancer in primary prevention (cancer occurrence) and in tertiary prevention (cancer recurrence). The second aim of this chapter will be to discuss the type and characteristics (duration, intensity) of physical activity associated with these effects both in primary prevention of breast and colon cancer and in cancer survivors. In other words, what types of exercise are most beneficial?

Evidence for the underlying mechanistic targets of physical activity interventions on the carcinogenesis process is also emerging. Studies suggest that exercise can exert its cancerpreventive effects at many stages during the process of carcinogenesis, including both tumour initiation and progression. This will be discussed in the third part of this chapter.

In the fourth part, the barriers to prescribe physical activity in physicians will be discussed as the published work provides sufficient evidence to suggest that physical activity is safe and well-tolerated even in cancer survivors and that oncologists can recommend to their patients physical activity after the completion of primary treatment. Finally we will discuss 
on the current guidelines on physical activity for cancer prevention and for cancer survivors, with guidance based largely on proven associations that exist between physical activity and specific comorbid conditions (such as heart disease or osteoporosis) to which cancer survivors are especially prone, or associations between physical activity and other factors, such as quality of life, functional decline, and fatigue. Effective strategies to increase physical activity will be discussed.

\section{Physical activity and colon and breast cancer prevention}

\subsection{Colorectal cancer}

\subsubsection{Review of the evidence on physical activity and colon cancer prevention}

Colorectal cancer is the cancer for which there is the largest number of evidences on the beneficial effect of physical activity (Friedenreich et al., 2010;Roberts \& Barnard, 2005). The overall level of scientific evidence on the beneficial effects of physical activity on the prevention of colon cancer is categorized as convincing (Friedenreich et al., 2010). This characterization is based on the definitions developed and used in the World Cancer Research Fund and American Institute for Cancer Research (the categories used are "convincing", "probable", "possible" and "insufficient"). Indeed on 51 studies conducted on colon and colorectal cancer, 43 demonstrated a reduction in cancer amongst the most physically active male and female participants with an average reduction from 20 to $30 \%$ amongst both men and women. This protective effect of physical activity for colon cancer is not found for rectal cancer (Friedenreich et al., 2010).

A recent meta-analysis (Wolin et al., 2009) measured the magnitude of the inverse association between physical activity and risk of colon cancer restricting analyses to studies where data for colon cancer alone were available (exclusion of rectal cancer). A total of 52 studies were included, showing a $24 \%$ risk reduction overall, and generally similar risk reductions when men and women were examined separately.

Evidence for a dose-response effect exists with greater risks reductions observed for higher levels of physical activity (Friedenreich et al., 2010).

\subsubsection{What type of physical activity is associated with prevention of colon cancer ?}

Although each study quantified activity differently limiting the ability to draw conclusion about the amount of physical activity necessary for the $24 \%$ risk reduction observed in the meta-analysis of Wolin et al. (2009) one example provides information. In the Nurses' Health Study, women who expended more than 21.5 metabolic-equivalent task (MET) hours per week (MET-h/wk) in leisure-time physical activity had a risk ratio (RR) of colon cancer of 0.54 (95\% CI, 0.33- 0.90), compared with women who expended less than 2 MET hours per week (Wolin et al., 2007). These levels are equivalent to brisk walking for some 5-6h per week in the most active and $0.5 \mathrm{~h}$ per week in the least active. Interestingly, Wolin et al. (2009) were able to examine the effects of physical activity domain (occupational vs leisuretime) and found that the results were similar. Additional research are needed on the type, intensity and duration of physical activity that may afford the greatest risk reduction.

Overall, the results from all studies indicate a dose-response relation (higher levels of physical activity have been associated with a reduced risk of colon cancer) with risk reduction present across a wide range of physical activity frequency and intensity.

Although a physically active lifestyle might be associated with other healthful behaviours, a number of characteristics of the findings indicate that higher levels of physical activity 
directly prevent lower colon cancer. The association has been consistently reported in many studies of various designs, in diverse populations, for men and women, and after statistical control for a variety of other lifestyle factors. A compelling finding is that the inverse association has been observed for both leisure-time and occupational activities, for which patterns of potential confounding lifestyle characteristics are likely to differ.

The characteristics of physical activity which could have a protective effect towards colon cancer remained controversial, the data of the literature being contradictory. The categorizations and the methods of measure of physical activity which differ between studies are probably at the origin of these inconsistencies. Measuring physical activity in all its components, type, intensity and duration is complex. Although the results are heterogeneous, the available evidence suggest that at least 30-60 minutes per day of moderate to vigorous intensity for at least 5 days per week is required to significantly reduce the risk of colon cancer (Friedenreich et al., 2010).

Concerning the optimal period of life to practice physical activity to maximize its protective effect, the authors recommend a regular practice of physical activity throughout the life.

\subsection{Breast cancer}

\subsubsection{Review of the evidence on physical activity and breast cancer prevention}

More than a dozen of cohort studies and an even more important number of case-control studies have examined the relations between physical activity and risk of breast cancer. More than three quarters of these studies have observed a beneficial of physical activity on breast cancer risk with a risk reduction about $25 \%$ when comparing the most to least active subjects. These results were confirmed and specified in a review of articles published between 1994 and 2006 on the relations between risks of breast cancer and physical activity (Monninkhof et al., 2007). The methodological quality of these articles was calculated on the basis of a statistical quality score and only articles of high quality were eligible: 19 cohort studies and 29 case-control studies. The higher quality cohort studies showed a risk reduction ranging from 20 to $40 \%$. A more recent overview of the existing evidence relating physical activity to breast cancer risk has been recently published (73 studies) (Friedenreich et al., 2010). They found a consistent reduction of about $25 \%$ of breast cancer risk when comparing the most to least active study participants (Friedenreich et al., 2010). Moreover, there is consistent evidence of a dose-response effect of decreasing risk with increasing activity levels.

\subsubsection{What type of physical activity is associated with prevention of breast cancer ?}

Most studies have investigated the association between breast cancer and leisure physical activity (walking, cycling, swimming, gymnastics) but few studies have included low intensity leisure physical activity such as gardening, home repair, stair climbing or housework (cleaning, washing, cooking, child care...) which probably led to an underestimation of total energy expenditure, especially among women who do not have access to a sport activity. The inclusion in the physical activity questionnaires of household activity is important because it is one of the main sources of physical activity for women in most developed countries. This is highlighted in the European cohort EPIC (The European Prospective Investigation into Cancer and Nutrition study), which showed that the risk of breast cancer was reduced in women in the top quartile of household activities (>90 MET$\mathrm{h} / \mathrm{wk}$ ) compared with women in the lowest quartile activities (<28 MET-h/wk): $-19 \%$ for 
postmenopausal women (HR: 0.81; 95\%CI, 0.70-0.93) and -29\% for premenopausal women (HR: 0.71; 95\%CI, 0.55-0.90) (Lahmann et al., 2007). These results based on a large and heterogeneous cohort (218 169 women from nine European countries, aged 20 to 80 years at baseline followed for an average period of 6.4 years) and which used standardized data collection of physical activity and that could control for all the potential confounding factors, provide additional evidence that moderate forms of physical activity, such as household activity, may be more important than less frequent more intense recreational physical activity in reducing breast cancer risk.

Similarly, E3N French study, which is the French part of the EPIC, refers to a decrease in the relative risk of $18 \%$ when household activities are of light intensity while this decline is $38 \%$ when the activity is of high intensity (Tehard et al., 2006), a dose-response effect being also shown for these household activities. A negative trend in risk of breast cancer associated with total recreational activity $(\mathrm{p}$ trend $<0.01$ ) and total physical activity ( $\mathrm{p}$ trend $<0.05$ ) was also observed.

Moreover, in review of Monninkhof et al. (2007), a trend analysis showed that the risk of developing breast cancer decreased by $6 \%$ per hour of physical activity added per week (assuming that the activity would be sustained over a long period of time) showing that this is the total amount of physical activity which is essential.

Overall, the analysis of the literature shows that at least 4 to 7 hours per week of moderate to vigorous physical activity would be required to produce a statistically significant decrease of the risk of breast cancer.

Several studies have attempted to determine the existence of a period of life in which the protective effects of physical activity would be maximum. In the absence of conclusive studies (pubertal period for some practice, adulthood for others), sustained lifetime physical activity appears as the most suitable preventive means (Friedenreich et al., 2010).

\subsection{Summary of the evidence on the protective effects of physical activity on colon and breast cancer}

The available evidence suggest that:

- $\quad$ at least 30-60 minutes per day of moderate to vigorous intensity for at least 5 days per week is required to significantly reduce the risk of colon cancer $(24 \%$ risk reduction of colon cancer risk when comparing the most to least active study participants).

- $\quad$ at least 4 to 7 hours per week of moderate to vigorous physical activity is required to produce a statistically significant decrease of the risk of breast cancer (reduction of about $25 \%$ of breast cancer risk when comparing the most to least active study participants).

\section{Effects of physical activity on colon and breast cancer survival}

Length of survival after colon cancer or breast cancer diagnosis varies widely, even after accounting for stage at diagnosis and treatment, suggesting other factors may also be important. Lifestyle habit such as physical activity is a modifiable behaviour with multitude of health benefits (Haskell et al., 2007) including beneficial effect on cancer survival. Indeed, several prospective studies have shown that the level of physical activity performed after the diagnosis of cancer significantly decreased overall mortality, cancer mortality and the number of recurrences of cancer. 


\subsection{Physical activity and breast cancer survival}

At least seven prospective studies have investigated the relations between physical activity and breast cancer survival (for a review see Barbaric et al., (2010).

The cohort of the Nurses' Health Study (121 700 women followed since 1976) has been the support of the first important study. This study focused on 2987 women with 280 breast cancer deaths and 8 years median follow-up (Holmes et al., 2005). Physical activity was measured by questionnaire every 2 years. The risk of death by breast cancer or breast cancer recurrence was reduced by 20 to $50 \%$ among women who walk 3 to $5 \mathrm{~h}$ per week (compared to those who walk less than $3 \mathrm{~h}$ per week). There was also a reduced risk of breast cancer recurrence and total mortality (Holmes et al., 2005).

The collaborative Women's Longevity Study (CWLS) of 4482 women with breast cancer followed for 6 years with 109 deaths reported a comparable decreased risk of breast cancer death and total death (Holick et al., 2008). These results were confirmed by the Women's Healthy Eating and Living Study (WHEL study) which reported a relative risk of recurrence reduced to 0.56 for women walking 30 minutes a day 6 times per week (Pierce et al., 2007).

Two smaller sized cohorts reported a decreased risk for total mortality but not breast cancer mortality with greater physical activity: the Life after Cancer Eidemiology (LACE) (Sternfeld et al., 2009) and the Health, Eating, Activity and Lifestyle (Heal) study (Irwin et al., 2008).

\subsection{Physical activity and colon cancer survival}

Three studies investigated the effects of exercise on cancer survival in patients diagnosed with colon (Meyerhardt et al., 2006a) or colorectal cancer (Haydon et al., 2006;Meyerhardt et al., 2006b).

Meyerhardt et al. (2006a) demonstrated that disease-free colon-cancer survival improved with increasing levels of physical activity ( $p$ trend $<0.01$ ). Based on the results of this study, it is suggested that a protective HR is observed with $>18$ total MET-h/wk or equivalent (HR= 0.51 ; 95\% CI: $0.26-0.97$, for 18 to 26.9 MET-h/wk); the protective HR does not improve beyond $27 \mathrm{MET}-\mathrm{h} / \mathrm{wk}$.

Two studies investigated the effect of physical activity on mortality in patients diagnosed with colorectal cancer. Haydon et al. (2006) demonstrated that persons who exercised at least once a week had improved disease-specific survival ( $\mathrm{HR}=0.73$; 95\% CI: 0.54-1.00, $\mathrm{p}=$ $0.05)$. The benefit of physical activity was largely confined to stage II-III tumours (HR $=0.49$; $95 \%$ CI: $0.30-0.79, p=0.01$ ), while no association was seen in stage I (least severe) or stage IV (most severe) tumours. The results of the study by Meyerhardt et al. (2006b) supported the role of post-diagnosis physical activity in decreasing cancer-specific mortality ( $\mathrm{p}$ for trend = 0.008 ) and overall mortality ( $p$ for trend= 0.003) (cohort of the Nurses' Health Study: 573 women whose colon cancer has been diagnosed (stage I, II or III), followed on average 9.6 years). Pre-diagnosis level of physical activity was not found to be predictive of mortality, whereas women who increased their activity level after diagnosis had an HR of 0.48 (95\% CI: 0.24-0.97) for colorectal-cancer deaths and an HR of 0.51 (95\% CI: 0.30-0.85) for all-cause mortality versus those with no change in activity. In contrast, among women who decreased their activity level there was a modest, though non-significant, increase in both cancerspecific and overall mortality.

All of these studies suggest that physical activity may confer additional benefits to those of the surgery, radiation therapy and/or chemotherapy for survival after treatment of breast or colon cancer. However, these results are observational and cannot formally identify a relationship of cause and effect. However the number of randomized trials 
testing physical activity interventions for cancer survivors is growing (Pekmezi et al., 2011). Moreover different research have started examining the impact of physical activity on surrogate/biologic markers of survival. All these studies are needed and are still ongoing.

\subsection{What type of physical activity is associated with beneficial effect on survival after colon or breast cancer?}

The review of literature shows that this beneficial effect of physical activity on survival is obtained regardless of the type of training: endurance, strength, or mixed. The intensity from which effects on survival are observed is $>9$ MET-h/wk which is equivalent to $30 \mathrm{~min}$ of brisk walking 5-7 times per week and this regardless of the level of physical activity before the diagnosis.

It is necessary to take into account the state of fatigue of the patients before prescribing a program of physical activity. In all cases, the prescription must be individualized and implemented very gradually. Indeed, "the AP is well tolerated, without adverse effects and oncologists should recommend physical activity to their patients after treatment" (Irwin et al., 2008) (see paragraph 7.2.2).

\subsection{Other benefits of physical activity for cancer survivors}

Cancer survivors are not only at increased risk for progressive disease but also a host of comorbid conditions (other cancers, cardiovascular disease, obesity, diabetes and osteoporosis), functional decline and premature death (Demark-Wahnefried et al., 2006a). The impact of exercise is beyond the effects on cancer survival rate as exercise is also associated with other benefits for cancer survivors: exercise is consistently associated with improved quality of life, and also is effective in improving physical functioning (oxygen capacity, cardiorespiratory fitness, other fitness or strength measures, flexibility and global health), anthropometric measures (weight status, body fat, waist circumference) and healthrelated biomarkers (blood pressure, heart rate, circulating hormonal levels) among cancer survivors (Demark-Wahnefried, 2006b).

These effects are obtained with the levels of physical activity recommended for cancer survivors (Haskell et al., 2007) (Table 1).

\section{Physical activity recommendations for colon and breast cancer prevention and for cancer survivors}

Physical activity recommendations for colon and breast cancer prevention and after cancer treatment are summarized in table 1.

\section{Physical activity during cancer treatment}

More than 40 studies of randomised trials published since 1980 have evaluated the effects of physical activity during adjuvant cancer treatments. Despite methodological limitations and small samples sizes, all reported that physical activity (light to moderate intensity exercise using bicycle or walking program and/or structured exercise program using treadmill, various other forms aerobic equipment and strength training, at least 3 times a week for 2030 minutes) is safe and feasible during cancer treatment. Physical activity can improve functional capacities, cardio-respiratory fitness and decrease the treatment-related 
symptoms (fatigue, nausea). Quality of life and sleep quality are also improved with physical activity (for a review see Kirshbaum, 2007 and Doyle et al., 2007).

\begin{tabular}{|c|c|c|c|}
\hline Type of physical activity & Intensity & $\begin{array}{c}\text { Duration } \\
\text { of each } \\
\text { session }\end{array}$ & $\begin{array}{l}\text { Frequency } \\
\text { per week }\end{array}$ \\
\hline $\begin{array}{l}\text { 1) Endurance exercices } \\
\text { PA of moderate intensity } \\
\text { (exemple: brisk walking) } \\
\text { OR } \\
\text { PA of high intensity } \\
\text { OR } \\
\text { Combination of both }\end{array}$ & $\begin{array}{l}\text { Moderate } \\
\text { Vigorous }\end{array}$ & $\begin{array}{l}30 \mathrm{~min} \\
20 \mathrm{~min}\end{array}$ & $\begin{array}{l}\text { at least } 5 \\
\text { times } \\
3 \text { times }\end{array}$ \\
\hline $\begin{array}{l}\text { 2) Resistance exercises } \\
\text { for muscle strength and } \\
\text { endurance }\end{array}$ & $\begin{array}{l}\text { 8-10 exercises } \\
\text { (with } 8-12 \text { repetitions for each } \\
\text { exercise) } \\
\text { on main muscle groups }\end{array}$ & $20 \mathrm{~min}$ & 2 times \\
\hline $\begin{array}{l}\text { 3) Stretching exercise for } \\
\text { flexibility }\end{array}$ & & & 2-3 times \\
\hline
\end{tabular}

- for cancer prevention : combination of 1$)+2)$,

- for cancer survivor: combination of 1)+2) +3).

Table 1. Recommendations of physical activity (PA: physical activity):

There are few recommendations on the type, duration and intensity of physical activity to be practised during the cancer treatment (chemotherapy and/or radiotherapy). In most of the studies, the proposed physical activity was of light to moderate intensity, at the rate of 3 to 5 times a week with a duration from 20 to 30 minutes by session.

For people who were sedentary before diagnosis, low-intensity activities such as stretching and brief slow walks should be adopted and slowly advanced.

\section{What biological mechanisms explain the associations between physical activity and colon and breast cancer}

Evidence for the underlying mechanisms involved in the pathways between physical activity and cancer is emerging. Numerous biological mechanisms have been proposed and in some cases tested in randomized controlled trials (for a review see (Friedenreich et al., 2010;Rogers et al., 2008; Chan \& Giovannucci, 2010).

In 2007 the World Cancer Research Fund examined associations for physical activity and several cancer types. They concluded that there is a statistical association between excess weight and some cancers including colon cancer and breast cancer in postmenopausal 
women. These results were confirmed by a large standardized meta-analysis (Renehan et al., 2008). The authors did a systematic review and meta-analysis to assess the strength of associations between BMI and different sites of cancer and to investigate differences in these associations between sex and ethnic groups. The objective was to determine the risk of cancer associated with a $5 \mathrm{~kg} / \mathrm{m}^{2}$ increase in BMI (which corresponds to weight gains of about $15 \mathrm{~kg}$ in men and $13 \mathrm{~kg}$ in women who have an average BMI of $23 \mathrm{~kg} / \mathrm{m}^{2}$ ). They analyzed 141 articles, including 282137 incident cases. In men, a $5 \mathrm{~kg} / \mathrm{m}^{2}$ increase in BMI was strongly associated with colon cancer (risk ratio $[R R]=1.24, p<0.0001$ ). In women, they recorded positive association between increased BMI and premenopausal $(p=0.009)$ and postmenopausal $(p=0.06)$ breast cancers. Associations were stronger in men than in women for colon $(p<0.0001)$ cancer. Associations were generally similar in studies from North America, Europe and Australia, and the Asia-Pacific region.

Mechanisms that link excess weight and cancer risk are not fully understood, though three hormonal systems -the insulin and insulin-like growth factor (IGF) axis, sex steroids, and adipokines - are the most studied candidates (Renehan et al., 2008). All three systems are interlinked through insulin (Figure 1).

Obesity and a sedentary lifestyle induce insulin-resistance and a compensatory hyperinsulinism. Chronic hyperinsulinaemia decreases concentrations of IGF binding protein-1 and IGF binding protein-2, which increases bioavailable or free IGF-I with concomitant changes in the cellular environment (mitogenesis and anti-apoptosis) that favor tumour formation (Rogers et al., 2008). Circulating total IGF-1, which is a major determinant of free IGF-1 concentrations, is also associated with an increased risk of colorectal cancer, and with premenopausal rather than postmenopausal breast cancer (Renehan et al., 2008). For postmenopausal breast cancer, the increase in risk might be explained by the higher rates of conversion of androgenic precursors to oestradiol through increased aromatase enzyme activity in adipose tissue. Furthermore, chronic hyperinsulinaemia might promote tumorigenesis in oestrogen-sensitive tissues, since it reduces blood concentrations of sexhormone-binding globulin, and in turn, increases bioavailable oestrogen (Calle \& Thun, 2004).

Beyond these mechanisms, other candidate systems include obesity-related inflammatory cytokines, altered immune response, oxidative stresses, the nuclear factor $\mathrm{kB}$ system.

The beneficial effects of regular physical activity on the risk of cancer can be explained, among others, by their protective effect on weight gain and the reduction of abdominal adiposity. Independently of the variations of fat mass, regular physical activity decreases insulinemia by increasing peripheral insulin sensitivity (Dwyer et al., 2011). The direct effects of physical activity on IGF-1 are contradictory, some studies showing a decrease and others no variation of plasma IGF-1 levels with physical activity (Duclos et al., 2007). Regular physical activity can also reduce the risk of occurrence and/or recurrence of breast cancer by reducing the endogenous production of the estrogens but also by increasing the SHBG (Sex Hormone Binding Globulin) (Duclos 2001; Chatard et al., 2004). By binding to estradiol or testosterone, the SHBG therefore reduces their biologically active free fraction. The production of SHBG also depends on diet (normal or hypo-calorie intake, high-fibre diet, etc.), and the effects of physical activity are sometimes confused with the effects of diet (Longcope et al., 2000). Figure 1 presents an explanatory hypothesis of the pathways linking physical activity and insulin/IGF-1 / sex hormones to breast cancer development. physical activity could act by inverting these various pathways. 
Rich diet + sedentarity

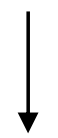

Increased fat mass*

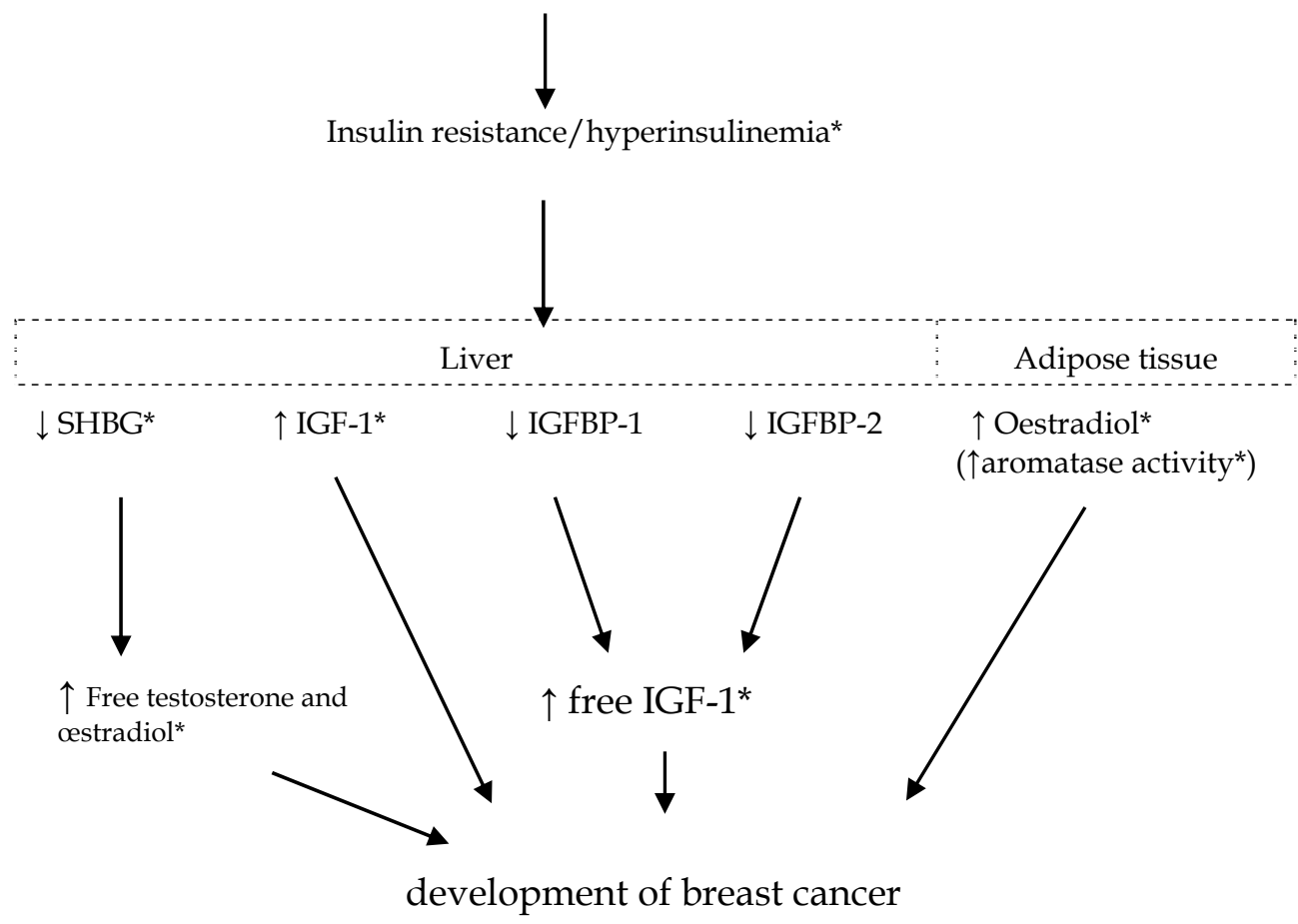

*: possible target and effects of regular physical activity

IGF-1 : Insulin like Growth Factor ; IGFBP-1 : Insulin like Growth Factor Binding Protein 1 ; IGFBP-2 : Insuline like Growth Factor Binding Protein 2 ; SHBG : Sex Hormone Binding Globulin

Fig. 1. Proposed mechanisms relating diet, physical activity and insulin to breast cancer

For colon cancer, the protective effects of regular physical activity marshal systemic effects of physical activity and local effects (Chan \& Giovannucci 2010). Physical activity could also increase colonic motility, although colonic motility has not been definitely linked to colon cancer risk.

Other biological mechanisms of protective effects of physical activity have been suggested, such as the reduction of oxidative stress and effects on immunity. It is clear that the beneficial effects of physical activity depend on many inter-connected mechanisms. However, the level of scientific proof in each case is a matter of debate and further research is needed in order to determine the preventive mechanisms for each type of cancer. 
In summary, exercise can alter biological processes that contribute to both anti-initiation and anti-progression events in the carcinogenesis process. However, more detailed studies are needed to examine each of the potential mechanisms contributing to an exercise-induced decrease in carcinogenesis in order to determine the minimum dose, duration and frequency of exercise needed to yield significant cancer-preventive effects, and whether exercise can be used prescriptively to reverse the sedentarity-induced and obesity-induced physiological changes that increase cancer risk (Rogers et al., 2008).

Moreover, the mechanisms of the beneficial effects of regular physical activity on survival after cancer treatment, and most importantly on the quality of life (decreased post-treatment fatigue, improved symptoms secondary to treatment) have yet to be determined (not to mention the need to know when to begin physical activity in relation to treatment, and at what dose: duration and intensity).

\section{Barriers to physical activity in cancer survivor and in their physicians}

Cancer survivors are not only at increased risk for progressive disease but also a host of comorbid conditions (other cancers, cardiovascular disease, obesity, diabetes and osteoporosis), functional decline and premature death (Demark-Wahnefried et al., 2006a). The impact of exercise is beyond the effects on cancer survival rate as exercise is also associated with other benefits for cancer survivors: exercise is consistently associated with improved quality of life, and also is effective in improving physical functioning (oxygen capacity, cardiorespiratory fitness, other fitness or strength measures, flexibility and global health), anthropometric measures (weight status, body fat, waist circumference) and healthrelated biomarkers (blood pressure, heart rate, circulating hormonal levels) among cancer survivors (Demark-Wahnefried et al., 2006a).

Therefore initiating and maintaining an exercise regimen long term should be generalized in the growing population of cancer survivors. In other words, cancer survivors should be encouraged to initiate and maintain physical activity.

However, adoption and maintenance of physical activity is a difficult challenge for healthy adults and is likely to be even more difficult after a cancer diagnosis. Concerning physical activity, cancer survivors are faced to two types of barriers:

- their own barriers to adoption and maintenance of physical activity

- barriers of their physicians to prescribe physical activity in cancer survivors.

This suggests that interventions to increase physical activity in patients should be multifactorial and multidirectional, i.e. directed towards patients and their physicians.

\subsection{Cancer survivor barriers to adoption and maintenance of physical activity}

As a result of the cancer diagnosis, surgery and adjuvant treatments some cancer survivors experience fatigue, depression anxiety, reduced overall quality of life (Irwin, Smith, McTiernan, Ballard-Barbash, Cronin, Gilliland, Baumgartner, Baumgartner, \& Bernstein 2008). All these comorbid conditions favor sedentarity.

Patients should be informed and educated on the role of physical activity, not only to aid in the prevention of cancer but also to improve survival rates following diagnosis.

Thus, oncologists and physicians should discuss with their patients the benefits of physical activity after a diagnosis of cancer, reassure them that exercise is safe and associated with improved overall survival and quality of life, and to refer them to a certified cancer exercise trainer who will prescribe an exercise program that is tailored to them. The oncologist and 
certified exercise trainer should also consider any preexisting conditions and adverse effects of treatment (Irwin et al., 2008).

It is necessary to take into account the state of fatigue of the patients before prescribing a program of physical activity. In all cases, the prescription must be individualized and implemented very gradually.

\subsection{Barriers of physicians to prescribe physical activity in cancer survivors: What physicians should know, understand and explain to their patients}

There is a reluctance of oncologists and of physicians to prescribe physical activity. Many elements prevent them from providing exercise advice: lack of sufficient knowledge of the benefits of being physically active after a cancer diagnosis, fear of side-effects of exercise (cardiovascular risks, lymphedema). Finally most physicians do not have the training or resources to develop individualized exercise prescription for cancer survivors.

\subsubsection{Physician should know, understand and explain the wide spectrum of health benefits of physical activity}

In addition to the risk of recurrence of the cancer, cancer survivors are also at risk of chronic fatigue, loss of muscle mass, weight gain. It should be noticed that the average weight gain after breast cancer treatment is $3-5 \mathrm{~kg}$, and that epidemiological studies have shown that weight gain after a cancer diagnosis is associated with an increased risk for recurrence and death compared with maintaining normal weight after diagnosis (Kroenke et al., 2005). Cancer survivors also have the same risks as the general population to develop cardiovascular diseases or metabolic diseases, or even they present an increased risk of developing these as obesity and a sedentary lifestyle are highly prevalent in cancer survivors. Specifically there is evidence that cancer survivors die of noncancer causes at a higher rate than persons in the general population (deaths being primarily from cardiovascular diseases and diabetes) (Carver et al., 2007).

As detailed in paragraph 3.4, physical activity can reduce risk of other chronic diseases (cardiovascular diseases and diabetes) on one hand, and on the other hand, physical activity may help subjects with cancer avoid dying from their cancer.

\subsubsection{Physician should know, understand and explain that physical activity in cancer survivor is safe and well-tolerated}

The published work provides sufficient evidence to suggest that exercise is a safe and welltolerated supportive intervention that oncologists can recommend to their patients after the completion of primary treatment.

In one of the largest studies to date, Courneya and colleagues examined the effects of aerobic exercise alone, resistance exercise alone, or usual care, on fitness, muscular strength, body composition, and quality of life in 242 breast cancer survivors initiating chemotherapy (Courneya et al., 2007). There were significant favorable effects of both aerobic and resistance exercise on multiple outcomes including self esteem, fitness, and body composition, as well as increased chemotherapy completion rates compared with usual care. Furthermore, no significant adverse events were reported; lymphedema did not increase or was not exacerbated by aerobic or resistance exercise. Recently, other clinical trials of women with breast cancer have shown no increased risk for or exacerbation of lymphedema from either aerobic and/or resistance exercise (Ahmed et al., 2006). 
Courneya and colleagues also completed a similar trial of aerobic exercise vs usual care in breast cancer survivors who had completed adjuvant treatment, and observed similar favorable effects of exercise on fitness and overall quality of life (Courneya et al., 2003). Overall, these, and other, studies have demonstrated that exercise is safe in cancer survivors and produces beneficial effects on quality of life and cancer-related symptoms with no adverse side effects.

A long-term concern in breast-cancer survivors starting an exercise program is lymphoedema. The few studies that have assessed this issue clearly showed that upper body exercise does not induce or exacerbate lymphoedema, and on the contrary, it would seem that a suitable AP allow to limit this risk.

\subsubsection{Physician should know and understand the influence of their beliefs on physical activity on the beliefs and physical activity of their patients}

General practitioners (GP) are cited as the primary source of information influencing healthy lifestyle decisions, but few studies have evaluated whether GPs' perceived barriers towards physical activity affect physical activity uptake in their patients. In type 2 diabetes patients, Duclos et al. (2011) have assessed the associations between GPs' perceived barriers to prescribing physical activity and type 2 diabetes patients' perceived barriers to adopting physical activity. Their findings showed that GPs' physical activity and GPs' perceived barriers, are associated with type 2 diabetes patients' physical activity. An effect of GPs barriers on patients' ones towards physical activity was depicted since the higher the GP's barriers score, the higher the type 2 diabetes patient's barriers score. Examining the nature of perceived barriers to physical activity in both type 2 diabetic patients (regarding physical activity practice) and their GPs (regarding physical activity prescription), common barriers emerged with a high score: "A low fitness level", "The fear of being tired", "Their actual physical health status, excluding diabetes", "The fear of suffering a heart attack". These common barriers are inconsistent with evidence-based medicine (Haskell et al., 2007). These results are consistent with the hypothesis that the beliefs of GPs might influence the beliefs of their type 2 diabetes patients. Finally, GPs' physical activity was positively correlated with their patients' physical activity.

It has been shown that endorsement of physical activity is more credible coming from a professional who practices physical activity (Abramson et al., 2000). GPs should practise physical activity themselves, not only for their own benefit, but also as a stimulus for physical activity of their patients (Duclos et al., 2011).

It remain to determine if this proves to be the case in cancer survivors. However this suggests that identifying and working on GPs' barriers but also promoting physical activity in GPs may improve the uptake of physical activity in their patients.

\subsubsection{Recommendations for physicians}

As in other clinical and non-clinical populations, cancer survivors should obtain clearance from their physician or oncologist program. This clearance is especially important in cancer survivors who are at high risk for late-occurring toxic effects secondary to treatment that can increase their risk of cardiovascular disease. Thus, appropriate screening procedures for cardiac and cardiovascular disease are recommended before an exercise program is started.

The prerequisite is that patients have obtained the prior agreement of their cancer specialist and that patients should be screened for osteoporosis, bone metastasis, cardiac toxicities, and lymphedema. 
Oncologist and primary care physicians should not lose sight of the fact that a substantial body of research shows the benefit of a healthy diet and regular exercise for reducing risk for many of the comorbid conditions (ie, other cancers, cardiovascular disease, diabetes, and osteoporosis) and side-effects (ie, fatigue and depression) for which cancer survivors are especially prone. Thus, oncology care providers can assist their patients by endorsing existing health guidelines for their patients and for themselves and encouraging their patients to take active roles in pursuing general preventive health strategies (Jones \& Demark-Wahnefried, 2006).

\section{Conclusion}

There is a large body of evidence that physical activity has an important role in prevention and management of cancer: physical activity reduces risk of breast and colon cancer, during and after cancer treatment physical activity ameliorate symptom experience, ameliorate treatment side effects, improve quality of life and reduce mortality and morbidity. As such, regular physical activity should be encouraged in all populations (general population, subjects at high risk of cancer, survivors of cancer... and in physicians) throughout all life. Now, the question is not: "why should I prescribe physical activity in my patients?" but "How initiating and maintaining physical activity in patients?". Initiating exercise is important; however, maintaining an exercise regimen long term is a significant challenge. Behavioural interventions are complex and involve multidisciplinary approach (patients, physicians, scientists, government, urbanists...). Whatever, it's time to get moving and it is never too late to get moving!

\section{References}

Abramson, S., Stein, J., Schaufele, M., Frates, E.\& Rogan S.: Personal exercise habits and counseling practices of primary care physicians: a national survey. Clin J Sport Med 10 (2000):40-48.

Ahmed, R.L., Thomas, W., Yee, D., \& Schmitz, K.H. (2006) Randomized controlled trial of weight training and lymphedema in breast cancer survivors. J Clin.Oncol., 24 (2006), 2765-2772.

Barbaric, M., Brooks, E., Moore, L., \& Cheifetz, O. Effects of physical activity on cancer survival: a systematic review. Physiother.Can., 62 (2010), 25-34.

Calle, E.E. \& Thun, M.J. Obesity and cancer. Oncogene: 23 (2004), 6365-6378.

Carver, J.R., Shapiro, C.L., Ng, A., Jacobs, L., Schwartz, C., Virgo, K.S., Hagerty, K.L., Somerfield, M.R., \& Vaughn, D.J. American Society of Clinical Oncology clinical evidence review on the ongoing care of adult cancer survivors: cardiac and pulmonary late effects. J Clin.Oncol. 25 (2007): 3991-4008.

Chan, A.T. \& Giovannucci, E.L. Primary prevention of colorectal cancer. Gastroenterology, 138 (2010): 2029-2043.

Chatard, J.C., Duclos, M., Rossi, D.\& Toutain, J. Androgens, skeletal muscle and muscle exercise. Progress in Urology, 14 (2004): 703-717.

Courneya, K.S. Exercise in cancer survivors: an overview of research. Med.Sci.Sports Exerc. 35 (2003): 1846-1852.

Courneya, K.S., Segal, R.J., Mackey, J.R., Gelmon, K., Reid, R.D., Friedenreich, C.M., Ladha, A.B., Proulx, C., Vallance, J.K., Lane, K., Yasui, Y., \& McKenzie, D.C. (2007) Effects 
of aerobic and resistance exercise in breast cancer patients receiving adjuvant chemotherapy: a multicenter randomized controlled trial. J Clin.Oncol.25 (2007): 4396-4404.

Demark-Wahnefried, W., Pinto, B.M., \& Gritz, E.R. Promoting health and physical function among cancer survivors: potential for prevention and questions that remain. $J$ Clin.Oncol. 24 (2006a): 5125-5131.

Demark-Wahnefried, W. Cancer survival: time to get moving? Data accumulate suggesting a link between physical activity and cancer survival. J Clin Oncol. 24 (2006b): 35173518.

Doyle, C., Kushi, L. H., Byers, T., Courneya, K. S., Demark-Wahnefried, W., Grant, B., McTiernan, A., Rock, C. L., Thompson, C., Gansler, T., \& Andrews, K. S. Nutrition and physical activity during and after cancer treatment: an american cancer society guide for informed choices. CA Cancer J Clin 56 (2007), 323-353.

Duclos, M. Impact of muscular exercise on endocrine functions. Annales d'Endocrinologie, 62 (2001): 19-32.

Duclos, M., Guinot, M., \& LeBouc,Y. Cortisol and GH: odd and controversial ideas. Appl.Physiol Nutr.Metab 32 (2007): 895-903.

Duclos, M., Coudeyre, E. \& Ouchchane, L. General practitioners' barriers to physical activity negatively influence type 2 diabetes mellitus patients' involvement in regular physical activity. Diabetes Care: in press

Dwyer, T., Ponsonby, A.L., Ukoumunne, O.C., Pezic,A., Venn,A., Dunstan,D., Barr,E., Blair,S., Cochrane,J., Zimmet,P., \& Shaw,J. Association of change in daily step count over five years with insulin sensitivity and adiposity: population based cohort study. BMJ 342 (2011): c7249.

Friedenreich, C.M., Neilson,H.K., \& Lynch,B.M. State of the epidemiological evidence on physical activity and cancer prevention. Eur.J Cancer 46 (2010): 2593-2604.

Haskell, W.L., Lee,I.M., Pate,R.R., Powell,K.E., Blair,S.N., Franklin,B.A., Macera,C.A., Heath,G.W., Thompson,P.D., \& Bauman,A. Physical activity and public health: updated recommendation for adults from the American College of Sports Medicine and the American Heart Association. Med.Sci.Sports Exerc. 39 (2007): 1423-1434.

Haydon, A.M., Macinnis, R.J., English, D.R., \& Giles, G.G. Effect of physical activity and body size on survival after diagnosis with colorectal cancer. Gut 55 (2006): 62-67.

Holick, C.N., Newcomb, P.A., Trentham-Dietz, A., Titus-Ernstoff, L., Bersch, A.J., Stampfer, M.J., Baron, J.A., Egan, K.M., \& Willett, W.C. Physical activity and survival after diagnosis of invasive breast cancer. Cancer Epidemiol.Biomarkers Prev. 17 (2008): 379386.

Holmes, M.D., Chen, W.Y., Feskanich, D., Kroenke, C.H., \& Colditz, G.A. Physical activity and survival after breast cancer diagnosis. JAMA 293 (2005): 2479-2486.

Irwin, M.L., Smith, A.W., McTiernan ,A., Ballard-Barbash, R., Cronin, K., Gilliland, F.D., Baumgartner, R.N., Baumgartner, K.B., \& Bernstein, L. Influence of pre- and postdiagnosis physical activity on mortality in breast cancer survivors: the health, eating, activity, and lifestyle study. J Clin Oncol. 26 (2008): 3958-3964.

Jones, L.W. \& Demark-Wahnefried, W. Diet, exercise, and complementary therapies after primary treatment for cancer. Lancet Oncol. 7 (2006): 1017-1026.

Kirshbaum, M.N. A review of the benefits of whole body exercise during and after treatment for breast cancer. J Clin Nurs. 16 (2007): 104-121. 
Kroenke, C.H., Chen, W.Y., Rosner, B., \& Holmes, M.D. Weight, weight gain, and survival after breast cancer diagnosis. J Clin Oncol. 23 (2005): 1370-1378.

Lahmann, P.H., Friedenreich, C., Schuit, A.J., Salvini, S., Allen, N.E., Key, T.J., Khaw, K.T., Bingham, S., Peeters, P.H., Monninkhof, E., Bueno-de-Mesquita, H.B., Wirfalt, E., Manjer, J., Gonzales, C.A., Ardanaz, E., Amiano, P., Quiros, J.R., Navarro, C., Martinez, C., Berrino, F., Palli, D., Tumino, R., Panico, S., Vineis, P., Trichopoulou, A., Bamia, C., Trichopoulos, D., Boeing, H., Schulz, M., Linseisen, J., Chang-Claude, J., Chapelon, F.C., Fournier, A., Boutron-Ruault, M.C., Tjonneland, A., Fons, J.N., Overvad, K., Kaaks, R., \& Riboli, E. Physical activity and breast cancer risk: the European Prospective Investigation into Cancer and Nutrition. Cancer Epidemiol.Biomarkers Prev. 16 (2007): 36-42.

Longcope, C., Feldman, H.A., McKinlay, J.B., \& Araujo,A.B. Diet and sex hormone-binding globulin. J.Clin.Endocrinol.Metab 85 (200): 293-296.

McNeely, M.L., Campbell, K.L., Rowe, B.H., Klassen, T.P., Mackey, J.R., \& Courneya, K.S. Effects of exercise on breast cancer patients and survivors: a systematic review and meta-analysis. CMAJ. 175 (2006):34-41.

Meyerhardt, J.A., Heseltine, D., Niedzwiecki, D., Hollis, D., Saltz, L.B., Mayer, R.J., Thomas, J., Nelson, H., Whittom, R., Hantel, A., Schilsky, R.L., \& Fuchs, C.S. Impact of physical activity on cancer recurrence and survival in patients with stage III colon cancer: findings from CALGB 89803. J Clin Oncol. 24 (2006a): 3535-3541.

Meyerhardt, J.A., Giovannucci, E.L., Holmes, M.D., Chan, A.T., Chan, J.A., Colditz, G.A., \& Fuchs, C.S.Physical activity and survival after colorectal cancer diagnosis. J Clin Oncol. 24 (2006b): 3527-3534.

Monninkhof, E.M., Elias, S.G., Vlems, F.A., van,d.T., I, Schuit, A.J., Voskuil, D.W., \& van Leeuwen, F.E. Physical activity and breast cancer: a systematic review. Epidemiology 18 (2007): 137-157.

Pekmezi, D.W. \& Demark-Wahnefried, W. Updated evidence in support of diet and exercise interventions in cancer survivors. Acta Oncol. 50 (2011): 167-178.

Pierce, J.P., Stefanick, M.L., Flatt, S.W., Natarajan, L., Sternfeld, B., Madlensk, L., AlDelaimy, W.K., Thomson, C.A., Kealey, S., Hajek, R., Parker, B.A., Newman, V.A., Caan, B. \& Rock, C.L. Greater survival after breast cancer in physically active women with high vegetable-fruit intake regardless of obesity. J Clin Oncol 25 (2007): 2345-2351.

Renehan, A.G., Tyson, M., Egger, M., Heller, R.F., \& Zwahlen, M. Body-mass index and incidence of cancer: a systematic review and meta-analysis of prospective observational studies. Lancet 371 (2008): 569-578.

Roberts, C.K. \& Barnard, R.J. Effects of exercise and diet on chronic disease . J Appl.Physiol 98 (2005): 3-30.

Rogers, C.J., Colbert, L.H., Greiner, J.W., Perkins, S.N., \& Hursting, S.D. Physical activity and cancer prevention: pathways and targets for intervention. Sports Med. 38 (2008): 271-296.

Sternfeld, B., Weltzien, E., Quesenberry, C.P., Jr., Castillo, A.L., Kwan, M., Slattery, M.L., \& Caan, B.J. Physical activity and risk of recurrence and mortality in breast cancer survivors: findings from the LACE study. Cancer Epidemiol.Biomarkers Prev. 18 (2009), 87-95. 
Tehard, B., Friedenreich, C.M., Oppert, J.M., \& Clavel-Chapelon, F. Effect of physical activity on women at increased risk of breast cancer: results from the E3N cohort study. Cancer Epidemiol.Biomarkers Prev. 15 (2006): 57-64.

Wolin, K.Y., Lee, I.M., Colditz, G.A., Glynn, R.J., Fuchs, C., \& Giovannucci, E. Leisure-time physical activity patterns and risk of colon cancer in women. Int.J Cancer 121 (2007): 2776-2781.

Wolin, K.Y., Yan, Y., Colditz, G.A., \& Lee, I.M. Physical activity and colon cancer prevention: a meta-analysis. Br.J Cancer 100 (2009): 611-616. 


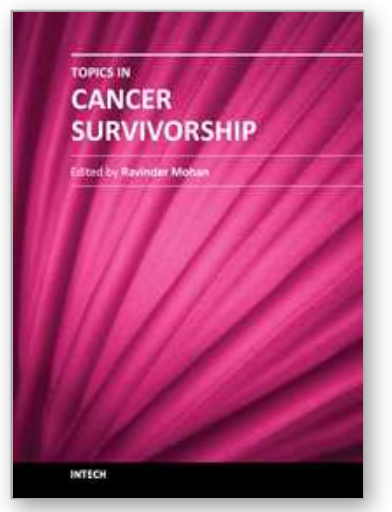

\author{
Topics in Cancer Survivorship \\ Edited by Prof. Ravinder Mohan
}

ISBN 978-953-307-894-6

Hard cover, 290 pages

Publisher InTech

Published online 27, January, 2012

Published in print edition January, 2012

Cancer is now the leading cause of death in the world. In the U.S., one in two men and one in three women will be diagnosed with a non-skin cancer in their lifetime. Cancer patients are living longer than ever before. For instance, when detected early, the five-year survival for breast cancer is $98 \%$, and it is about $84 \%$ in patients with regional disease. However, the diagnosis and treatment of cancer is very distressing. Cancer patients frequently suffer from pain, disfigurement, depression, fatigue, physical dysfunctions, frequent visits to doctors and hospitals, multiple tests and procedures with the possibility of treatment complications, and the financial impact of the diagnosis on their life. This book presents a number of ways that can help cancer patients to look, feel and become healthier, take care of specific symptoms such as hair loss, arm swelling, and shortness of breath, and improve their intimacy, sexuality, and fertility.

\title{
How to reference
}

In order to correctly reference this scholarly work, feel free to copy and paste the following:

Duclos Martine (2012). Physical Activity and Cancer: It is Never Too Late to Get Moving!, Topics in Cancer Survivorship, Prof. Ravinder Mohan (Ed.), ISBN: 978-953-307-894-6, InTech, Available from: http://www.intechopen.com/books/topics-in-cancer-survivorship/physical-activity-and-cancer-it-s-never-toolate-to-get-moving-

\section{INTECH}

open science | open minds

\author{
InTech Europe \\ University Campus STeP Ri \\ Slavka Krautzeka 83/A \\ 51000 Rijeka, Croatia \\ Phone: +385 (51) 770447 \\ Fax: +385 (51) 686166 \\ www.intechopen.com
}

\author{
InTech China \\ Unit 405, Office Block, Hotel Equatorial Shanghai \\ No.65, Yan An Road (West), Shanghai, 200040, China \\ 中国上海市延安西路65号上海国际贵都大饭店办公楼 405 单元 \\ Phone: +86-21-62489820 \\ Fax: $+86-21-62489821$
}


(C) 2012 The Author(s). Licensee IntechOpen. This is an open access article distributed under the terms of the Creative Commons Attribution 3.0 License, which permits unrestricted use, distribution, and reproduction in any medium, provided the original work is properly cited. 